\title{
CHAPTER 49
}

\author{
DESTRUCTION CRITIRIA FOR RUBBLE-MOUND BRRAKWATERS
}

By Adelkis J. Kogan, Docteur Ingénieur

Laboratolre National d'Hydraulique, Chatou, FRANCE.

\section{ABSTRACT}

The general purpose of the author's research undertaken in the "Laboratoire National d'Hydraulique" was to study wave action on rubble-mound breakwaters with regular (periodic) waves on the one hand and irregular (random) wind generated waves on the other, and to compare the effects of these two types of waves by use of the storm duration $t$. With a first series of periodic waves experiments we have obtained the destruction of the breakwater's cover-layer for different storm durations $t$, by varying $H$ and $T$. The mass of armor units remained constant. The angle of the slope, according to the seaward equilibrium profile could be considered as constant.

For the destruction cases we obtained a risk criterion:

$$
\frac{t}{T}=-A \cdot \log \left(\frac{E^{2}}{V T}\right)+B
$$

which provides the storm duration $t$, knowing $H, T$ and $\nu$.

Then for a second series of random wand generated waves experiments we eliminated $t$ and found that the constant periodic wave height ( $\mathrm{H}_{\text {dest }}$ ) is equal to the "significant wave height" $\left(\mathrm{H}_{1 / 3}\right)$ for the random waves. This is an experimental demonstration of the justifiable use of $\mathrm{H}_{1 / 3}$ as "project wave height".

\section{INTRODUCTION}

1.1. Analysis of Classical stability formulas.

First of all an analysis of classical empirical and semi-empirical stability formulas was necessary to show the importance of some variables and the absence of others. Thus formulas of CASTRO, IRIBARREN, MATHEWS, EPSTEIN and TYRELI, IRIBARREN and NOGALES, RODOLF, LARRAS, IRIBARREN (modified by HUDSON), HEDAR, HENNES and LEONOFT, BEAUDEVIN, HUDSON (or W.E.S. formula) have been analysed and were adapted to "I.N.H." commonly used notation. Afterwards, they were transformed to show common parameters and to verify their dimensional homogeneity (1). Only two of them are homogeneous: IRIBARREN's (modified by HUDSON) and HUDSOI's formulas. Stability formulas have the following general aspect: 


$$
L=H^{3} \cdot F
$$

where $F=k \cdot f_{1}(\delta) . f_{2}(\alpha) \ldots$

"Wo $g^{\prime}$ them (the formulas of WhTw.WS and RODOIF) have the aspect $\mathrm{H}=\mathrm{H}^{2}$.T.F, but they are not uced in rractice.

The stochastic character of waves and the time of action, or otherwise storm duration, do not annear in the previous formulas. On the other hand, enjuneers use more and more the "significant wave helght" $\mathrm{I}^{+} \mathrm{I} / 3$ as "project "ave height" for maritzre structures.

1.2. lis in purnose.

The main nurpose was to intrnduce the "ture of action" $t$ (or storm durgtion) into the crnsinertion of rubble-mound breakwater's stabilzty and to verufy experimentally the empirical and theoretical $(2,3)$ assumption that $\mathrm{H}_{1 / 3}$ is really the representative and afterwards destructive mear. wave heloht value of a random sea.

The reasonin on multi-layered breaiswaters:

(a) Cover-layer's profile can be modlfied till stabillzation. When second layer is reached then destruction is imminent. Smaller armor units of the secon" cover-layer can no longer resist wave attack.

(b) It is easier to observe the comnlete destruction of the coverlayer than to measure the number of displaced armor units.

(c) Wave height or period of random waves are not known a priori. Duration of wave action on the breakrater is the only parameter for comparison between periodic and random waves.

Therefore we have chosen as a criterzon of comparison the complete destruction of the cover-layer in the same time, obtained one time from periocic waves ( $H$ and $T$ constant) an in another time from random waves ( $H_{i}$ and $T_{i}$ random values). Thus, eliminating the parameter $t, H$ and $H_{i}$ can be compared as well as $\mathrm{T}$ anc $\mathrm{T}_{i}$.

Figure I shows the general configuation of "I.N.H." research facillties as well as pertinent dimensions in meters.

\subsection{Similltude.}

The ascumption was made that the inertia forces are very much larger than viscous forces. In general, similitude of the two flows with free surface requires two con itions:

$$
\begin{aligned}
& F_{1}=F_{2} \\
& R_{1}=R_{2} \text { (or in default of: } R_{1}>R_{c} \text { and } R_{2} \geqslant R_{c} \text { ). }
\end{aligned}
$$




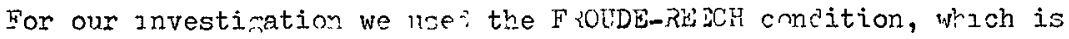
essertial for mocel studies in open chamele with stronsly turbulent flors. Nevertheless, we dad not throw acz de the assumition of the immortance of the conilion of BAYNCDS. The dimensions of the model were sufficiently small th + infiltration on percolotion flor's accomnany the rave attack on armor unitr.

The scalo 1:40, has been cisozen acogming to the dumencions of "L." .t." research frcillties. Siecifia wrav $t_{j}$ of wator uzer" durino expormontation ins assumed to he ejual to 1.0n. Difference of specific gravity between mocel water $(1.00)$ and sea water (1.025 - 1.029 , according to ralinity) is bis ennush to be importent if moiel investigotion is relater to fiel construction (4). Our study wis theoretacal; therefore wo did rot take the difference into account. The mass per unit-voluve of arinor units was

$$
P_{8}=2.6 \mathrm{t} / \mathrm{m}^{3}
$$

\section{PIRIODIC WAVES}

\subsection{Introduction.}

The variahles $\mathrm{H}$ and $I$ were constant during each exnerment and the followno values were chosen for these variables:

$\mathrm{H}=0.05,0.075,0.10,0.125 \mathrm{~m} .($ (.e. $2,3,4,5 \mathrm{~m}$. in nature) approximately.

$T=0.948,1.265,1.581,1.897 \mathrm{sec}$. (․e. $6,8,10,12 \mathrm{sec}$. in nature).

It was easy to set the wrove generatim st fi: purind desired with the channel emnty. Aftemaris, the model was constructer, the channel filler with water to the 1 utel $\mathrm{C.35} \mathrm{m}$. (corresponing to $1^{l} \mathrm{in}$. in nature), the resictance type wave cauces colibratei and, then the generator starter. The wave hez. "it was inoremsed from zero to the desirer valus ex? then remain d constent ourin, the wole experzent.

\subsection{Model.}

Fioure 2 shows one of the breakwater rofilen stilico. It is a ty re commonly eimlnyer? with throe cover-layers. The same amor unts of srecific gravity 2.6 , wel ghed one by one and arranged alveve in the some wav, have been use' throughout all experiments.

Particle size distributions woed for each layrr tere:

$$
\begin{aligned}
& A=50-80 \mathrm{i} \cdot \text { (i.e. } 3-5 t \text { in nature) } w 1 \text { th } h_{\mathrm{in}} \simeq 63 \mathrm{c} \cdot(2.0 .4 t) \text {. } \\
& B=20-50 \approx \text { (i.e. } 2.5-3 t \text { in noture) wath } B_{m} \simeq 37 \mathrm{~g} \cdot(1.0 \cdot 2.3(1, t) \text {. } \\
& c=5-258 \cdot \text { (1.e. } 0.32-1.6 t \text { in nature) } w 2 \text { th } C_{r_{t}} \simeq 118 .(1 . e \cdot 0.7 t \text { ). }
\end{aligned}
$$


Where $A_{m}$ is the median of $A, B_{m}$ of $B$ and $C_{m}$ of $C$.

The middle-layer armor units were coloured blne. The colournn made it easier to know the moment at whlch the midilo-layer was reeched in the process of destruction.

Water depth on the sea side was arrays constant and equal to $0.35 \mathrm{~m}$. (i.e. $14 \mathrm{~m}$. in nature). The angle of breakwater slone varied from 30 to 36 degrees in stens of 2 degrees.

\subsection{Experiments with poriodic waves.}

Every experzment last:d, as a rule, 3 hours 45 minutes (1.e. 24 $\mathrm{hrs}$. in nature) if the cover-layer was stablised. Tf the destruction of the cover-layer was achieved before $3 \mathrm{hrs}$. $45 \mathrm{~min}$., we stopned the experiment. If the destruction was imminent around $3 \mathrm{hrs} .45 \mathrm{~min}$. , we prolonged the experiment until somplete destruction was obtained. Sixteen experiments were made for every angle of breakwater slope: 4 for every wave period $(0.948,1.265,1.581,1.897 \mathrm{sec}$.) for each wave height, $(0.05,0.075,0.10,0.125 \mathrm{~m}$. a.snroximately).

Some experiments were omitted when no influence of the brealwater slove was obtained (for instance for $\mathrm{H}=0.05 \mathrm{~m}$. and $\mathrm{T}=0.948 \mathrm{sec}$.). At the end of the experiment we dretr the now profilc on the glass-wall and we nhotographed it. The destruntion of the cover-laver was obtained in 13 cases.

Ten minutes after the waves were fully developer, a record of the clapotis between the model and the wave generator was made. From thiz record we obtained the value of $\mathrm{H}$, which we will later compare with the destructive mean value of the irregular wave height.

\subsection{Seaward equilibrium profile.}

During the first minutes of every experiment we observed the tendency of attacking waves to move armor units from the upper portion of the slope to the lower portion. After some minutes a new profile was "carried" on the seaward face of the breakwater (Figure 3, profile DA BC). The new discontinuous slope was composed of three different slopes, one of which (the slope $A B$ ) was flatter than the initial one.

From this moment onwards, the destruction of cover-layer progressed, with a good approximation, parallel to the new slopes. Comparison between corresponding slopes for varlous tests ( 1 , section 4.33 ) shows no big differences between them. Their mean values were:

$$
\begin{aligned}
& \tan \alpha_{1}=1 / 1.059, \tan \alpha_{2}=1 / 2.627, \tan \alpha_{4}=1 / 1.278 \\
& \alpha_{1} \propto 43 \quad \alpha_{2} \simeq 21 \quad \alpha_{4} \simeq 38
\end{aligned}
$$

Therefore profiles with different slopes of $30,32,34$, and 36 degrees were transformed, after a few minutes, to an iden ${ }^{+} \mathrm{cal}$ discontinuous seaward profile; i.e. to an icentical reflection slone for 
incldent wives. Thus, values measured durang all these experiments heve becr veed to:ethar for colculations.

?5. Characterization of the risk of cover-loycr destruction.

a) Study of parameters: $Y=\log \left(\frac{\mathrm{H}^{2}}{\mathrm{~T}}\right)$ and $X=\frac{t}{\mathrm{~T}} \cdot 10^{-3}$

We furst specify $r$ as the sarple coefficient of correlation and as the value for the true bivariate distribution of $X$ and $X$.

:e obtianed aectmation of the cover-19yer in 13 cases $(n=13)$. Trus be have stuciser the coefficient $r$ for the bivariate dictrabution

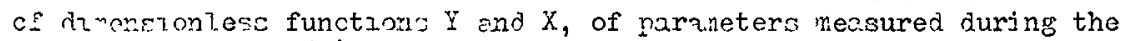
above cxperiments (5). Pursuin the celcilation of Table 1 , we obtained:

$$
\begin{aligned}
& \sigma_{x}^{2}=\frac{D_{x}}{n^{2}}=7.297 \quad \sigma_{x}=2.701 \\
& \sigma_{y}^{2}=\frac{D_{y}}{n^{2}} \quad \sigma_{y}=0.063 \\
& c \quad=n \cdot \Sigma X Y-\Sigma X \cdot \Sigma Y=-23.008 \\
& \text { and } r \quad=\frac{C}{\sqrt{D_{X} D_{y}}}=-0.796 \quad=0.796
\end{aligned}
$$

We will now tert it; signzfacance with the $z$ - Transformation of LISI'ER:

$$
z \quad=1 / 2 \log \left(\frac{1+r}{1-r}\right)
$$

which le distributed aproyimnte? accordinis to a GaUSS law of expectation:

$$
\xi=1 / 2 \log \left(\frac{1+P}{1-P}\right)
$$

ann stonsard deviation:

$$
\sigma=\frac{1}{\sqrt{n-3}}
$$

For $r=-0.796$ we obtained $z=-1.088$ and for

$$
n=13: \quad 1 / \sqrt{n-3}=0.3164
$$

If no real cor elotion evists for the true bivariate distribution of $y, X(1 . e . P=0)$, the variable $u=z / \sigma$ is distributed according to $a$ unit normal distribution, then $u=-3.44$.

The probobility of finitin a value less than or equal to $u=-3.44$, if $\rho=0$, is equal to 0.0003 , i.e. $\operatorname{Pr}(u \leqslant-3.44, p=0)=0.0003$. Thus the correlation observed in our sample corresponds to a strong one for the true bivariate distribution of $y$ and $X$. 


\begin{tabular}{|c|c|c|c|}
\hline 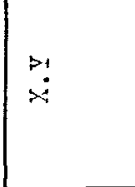 & 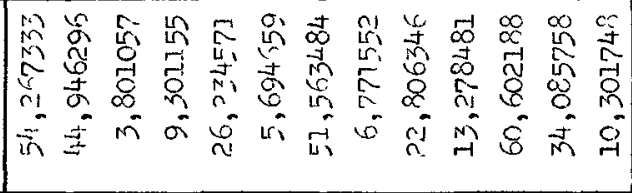 & 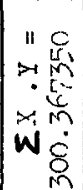 & 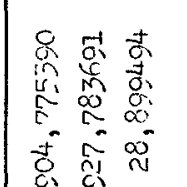 \\
\hline 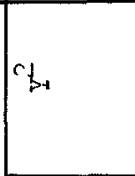 & 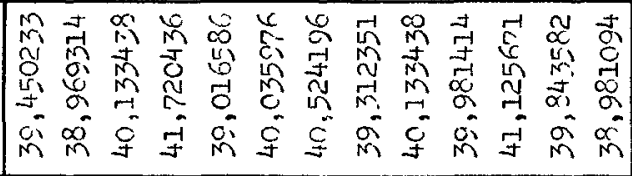 & 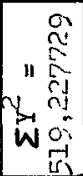 & 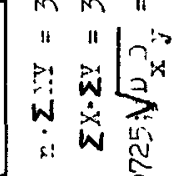 \\
\hline$r x$ & 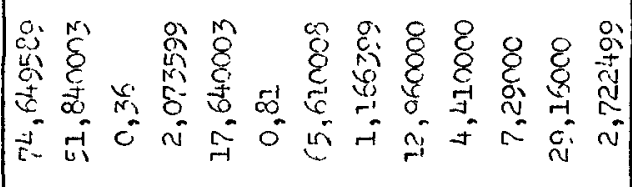 & 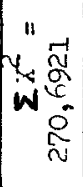 & 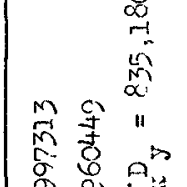 \\
\hline 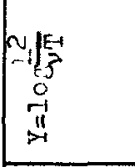 & 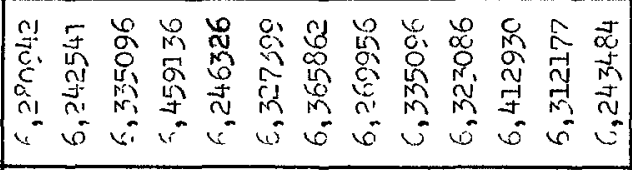 & & 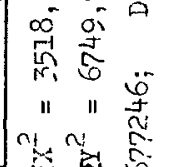 \\
\hline 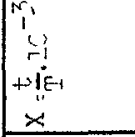 & 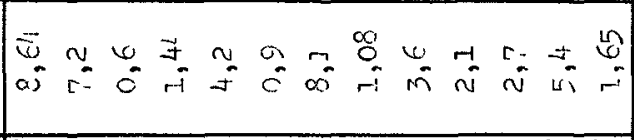 & 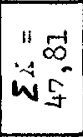 & \\
\hline a & 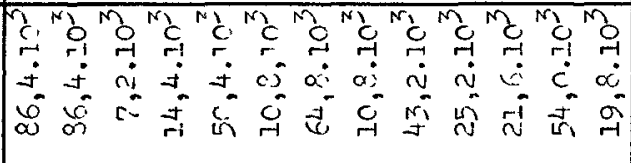 & 焉 & 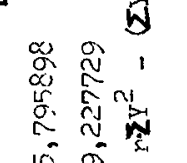 \\
\hline W & 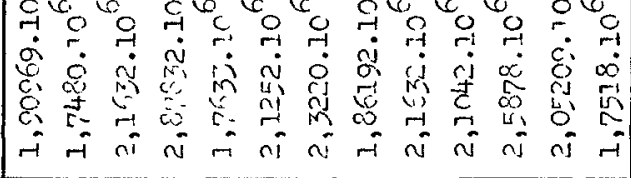 & $N_{a}$ & $\overbrace{b}^{n !} \overbrace{b}^{\prime \prime}$ \\
\hline 等 & 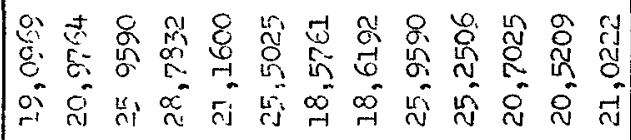 & " & \\
\hline & 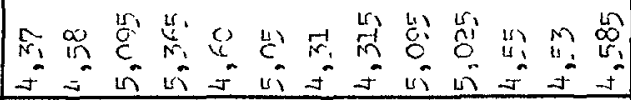 & 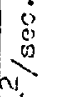 & 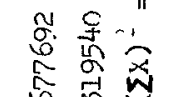 \\
\hline & 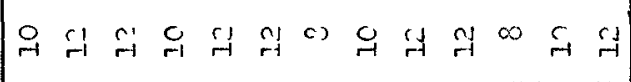 & ${ }_{1}^{1} c$ & \\
\hline & 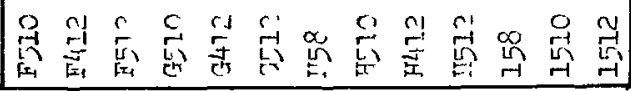 & 2 & \|\|$_{1 \rightarrow 1} A^{i x}$ \\
\hline
\end{tabular}


The line $r$ re serion of $v$ on $Y$ Iz:

$$
X=b \cdot Y+a
$$

wath a wim-tely :

$$
\mathrm{b}=\frac{\mathrm{C}}{\mathrm{D}_{y}}=-34
$$

and

$$
a=\overline{\mathbf{x}}-\mathbf{b} \overline{\mathrm{Y}}=218
$$

so thet $\left(\sin _{0} \cdot 4\right): \frac{t}{\mathrm{~T}}=-34.10^{-} \log \left(\frac{\mathrm{H}^{2}}{\nu \mathrm{T}}\right)+218 \cdot 1 n^{3}$

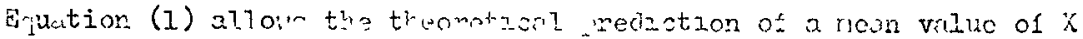
for a giva vilue ofv. But the vilue rearl: on the partjcular

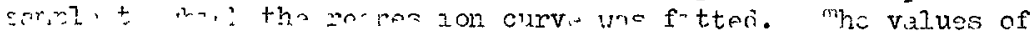
the sample are sunfinct th ranoou fluctuations, so that we must

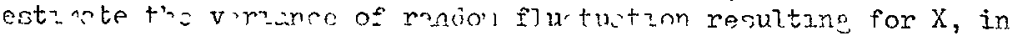
order to nitz :t, ly esti" ite it confirence interval $(G)$ :

$$
S_{x}^{2}=\left[\frac{1}{n}+\frac{(Y-\bar{Y})^{2}}{\sum\left(Y_{1}-\bar{Y}\right)}\right] S_{2}^{2}
$$

whore $n$ is the nuiber of variables of our samale anci

$$
s_{2}^{2}=\frac{1-r^{2}}{n-2} \sum_{\text {condzional }}\left(x_{l}-\bar{X}\right)^{2}
$$

Is the estimate of

the condational varionce.

But if: "e are will $3 r$ : to concuior $X$, not as a mean value for $Y$, but 25 a forecast of the norticmat value which $X$ obtains, we hove to add the proper variance of $X$ (con itzonal vernerce $s_{2}^{2}$ ) to this

varience of the linear regression curve:

$$
\begin{aligned}
s_{x}^{2} & =\frac{1-r^{2}}{n-2} \sum\left(X_{1}-\bar{X}\right)\left[\frac{1}{n}+\frac{(Y-\bar{Y})^{2}}{\sum\left(Y_{1}-\bar{Y}\right)^{2}}+1\right] \\
\text { or: } s_{x}^{2} & =\left(1-r^{2}\right) \frac{n-1}{n-2} \sigma_{x}^{2}\left[\frac{1}{n}+\frac{(Y-\bar{Y})^{2}}{(n-1) \sigma_{y}^{2}}-1\right]
\end{aligned}
$$

The preducted value of $X$ for a given $Y$ is aproxinately distrubuted

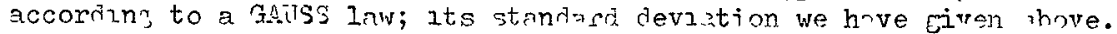
The tebles of tho CNiss law clve the roduced limats of entervala, whioh cover the true vilue inth a glven noob?hifity. Iimits n $n^{\circ}$ confucense

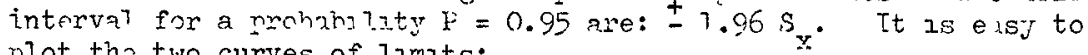
plot the two curves of limits:

$$
\begin{aligned}
F(y) & = \pm 1.06 . \sigma_{x} \sqrt{\left(1-r^{2}\right) \frac{n-1}{n-2}\left[\frac{1}{n}+\frac{(Y-\bar{Y})^{2}}{(n-1) \sigma_{y}^{2}}+1\right]} \\
& = \pm 3.35 \sqrt{1.077+\frac{(Y-6.319)^{2}}{0.048}}
\end{aligned}
$$

b) Studv of Dirameters: $Y=\log \left(\frac{\mathrm{H}}{g \mathrm{~T}^{2}}\right), X=\frac{t}{\mathrm{~T}} \cdot 10^{-3}$ 
According to the same ar urient we obtazned:

$$
r=0.336
$$

$r$ is too small, therefore we cannot have any conclusion about the real coofficient of correletion of the true bivari te distribution of $\mathrm{Y}$ and $\mathrm{X}$.

\section{c) Conclusion}

The equation: $\frac{t}{T}=-A \cdot \log \frac{H^{2}}{\nu T}+R$ permits us to determane the time $t$ needed for the destruction of the cover-layer, knowing $\mathrm{H}$, $T$ and $\nu$. The parameter $t / T$ can also be considereh is an index of fatigue of the structure: poriod $T$ is constant, for perionic waves, therefore $t / T$ represents the number of shocks recejved by the structure till its destruction. We ascertinner also that thu parameter $\mathrm{H}^{2} / \nu \mathrm{T}$ is strongly correlated whth $\mathrm{t} / \mathrm{T}$, whereas $\mathrm{H} / \mathrm{gT}^{2}$ is not.

Further analysis of the strons correlation between $t^{2} / \nu \mathrm{T}$ and $t / T$, recalline at the same time thit $\mathrm{H}^{2}$ is an enerr f-rtor, we conclude from this eruation thet we can rel it inve enerpy to wave perro $0^{*}$ ond storm durition.

\section{RANDOM WTIND GENIRITID WAVES}

\subsection{Production of whin waves.}

Bandom waves were induced by an aln flow over a fetch of $30 \mathrm{~m}$ - maximal length. Water depth was, as for the perioric waves, $0.35 \mathrm{~m}$. and wind speeds up to $9.4 \mathrm{~m} / \mathrm{sec}$. were obtanned. We observed during the first tests, that a constant wind flow over the water surface cenerated quite periodic waves. After some investrgations (1, section 5.31) we connected to the blower's motor an electro-mechanice] system, which produced different cycles of start-off and stons. Whth this system and the varlation of wind velocity and fetch we obtalned a sufficient varlety of wave heights and perlods. Surfice elevatione were mcasured, with the help of a sonar, every 0.1 sec. and punched on a paier tape. A resistance type wave gauge placed at the same location gave an immediate picture of the waves.

\subsection{Experiments with wand generated waves.}

The purpose of this serles of experiments was to destroy the total thickness of the cover-layer alons the model in anproximately the same time as in experiments with periodic waves. Several experumenta, with varistions of wind velocity, fetch and motor cycles, were nocessary to obtain this.

Every experiment involved the follown onerations:

(a) Construction of the model and the filling of the chunnel wath 
water to a depth of $0.35 \mathrm{~m}$.

(b) Choice of a motor-cycle, a fetch and a wind velocity.

(c) Calibration of the resistance wave gauge.

(d) Regulating of wind deflector.

(e) Starting of blower.

(f) Ten minutes afterwards (time necessary to obtain fully developed waves) the first record with the sonar and at the same time with the resistance wave gauge. Duration of records: 4 minutes.

(g) Continuous observation of the profile's transformation, especially a proachung any time in which we obtained the destruction with periodic waves. If the maximal time of perıodic waves destruction was exceeded we stcpped the experiment. If we observed that we were near to a "same time destruction" a second wave record was obtained.

(h) At the end of the experiment we drew the new profile on the glass-wall and photographed the profile.

3.3. Seaward equilibrium profile.

During the random waves experiment series we observed the same evolution of the equilibrium profile as in the periodic waves experiment series. We generally distinguzshed 3 new slopes with mean values:

$\tan \alpha_{1}=1 / 0.96, \tan \alpha_{2}=1 / 2.78, \tan \alpha_{4}=1 / 1.37$

$$
\alpha_{1} \simeq 46 \quad \alpha_{2} \simeq 19 \quad \alpha_{4} \simeq 36
$$

The comparison with the values obtained from the periodic waves series shows no big difference between corresponding slopes.

\section{4. - COMPUTER ANALYSIS OF THE RECORDS}

Every tape record contained 2,400 values. It was converted in an I.B.M. 47 machine to punched cards. The "Service E.R.C.A." of "Electricité de France" is equipped with a C.D.C. 6600 digital computer. Another facility, the System D.D. 280 made graphical output possible.

The process of surface elevation was assumed stationary and ergodic, the frequency distrubution similar to a GAUSSIAN process.

4.1. Autocorrelation function, Spectral density and relative width $\mathrm{E}$.

The purpose of this computer calculation was to investigate the randomness of the wind waves produced in our channel. Our records have been discreetized into observations $x_{i}(t)$. We have obtained 
the autocorrariance function from the following equation (7):

$$
W(J)=\frac{1}{N-J} \sum_{i=1}^{N-J} X(I) \cdot X(I+J)
$$

and than the zutocorrelation function:

$$
R(J)=\frac{W(J)}{\frac{1}{N-J} \sum_{I=1}^{N O} X(I)^{2}}
$$

Thus the first approximotion of the spectral density was:

$$
\operatorname{tP}(J)=W(0)+2 \sum_{k=1}^{199} W(k) \cdot \cos \left(\frac{K \cdot J \pi}{200}\right)+W(200) \cos (J \cdot \pi)
$$

and finally after smoothing by HAMNING:

$$
S P(J)=0.23 . L F(J)+0.54 \operatorname{LP}(J+1)+0.23 \mathrm{LP}(J+2) .
$$

An example of craphical presentation is given on Fugure 5. Values of $\varepsilon$ have varied from 0,70 to 0,97 .

4.2. Joint distrabutions of $\mathrm{H}$ and $\mathrm{T}$ (Fig. $6^{\prime}$.

With the help of zero up-crosszn s of the sea lovel we have obtained the wave heights and perlods for every samnle. The principal dxfficulty was the determination of the mean leve].

The different cycles of start,.of $i$ and stope of the blower provoked sezcher. As the raves were ranciom tris vas not of umyortance from an enersy count of view, but was very important for the defination of wave heights and periods; nevcr heles: the mothor utiluzed was the zero-uncrosings one. Thorefore we harr eliminat the seicher watl the help of a moving-mean over 75 points. H and 1 values $h$ re beon classes in increasinj orrer, to evaluate the mean veluos $\mathrm{H}_{\mathrm{n} / \mathrm{m}}, \mathrm{T}_{\mathrm{n} / \mathrm{a}}$ (where $n=3,2,3$ and $m=1,2, \ldots, \ldots, 10)$.

Recalling that $H$ har boon defined is the conatant periodic wave hei ht for the experiments Hurin; which we obtanned the destruction of the cover-layer, we have calculste? the ratios:

$$
\mathrm{H}_{\text {dest. }} / \mathrm{F} \mathrm{H} / 3 \text { and } \mathrm{H}_{1 / 3} / \overline{\mathrm{H}}
$$

a) for $\mathrm{H}$ dest $/ \mathrm{H} / \mathrm{H}$ we have obtained values going from 0.87 to 1.10 , with a mean of $1.00^{1 / 3}(E x . F(g, 6)$. Thrs is an experimental denonstration of the empirical and theoretical assu'ntion that $\mathrm{H}_{7} / 3$ is the rerresentative wave height and thus good to be used as a project wave hoight.

b) for $\mathrm{H} / \mathrm{f}$ we have obtained values going from 1.33 to 1.48 . Through

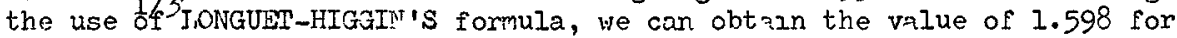
the same parameter. 
Ocean observations (8) have given vilues golng from 1.37 to 1.85 .

c) The comporison between constent periods of forloric wives an random periocs of wind rancrated wives dic not give a si gni ricurt relationship between them becavie of the different ranges; i.e. nerlo $i$ ic waves nerlod varied from 0.948 to 1.897 sec., but the random wand generated wave nemor varzei from 0.7 to 1.5 sec. Neverthelese in some cases, where constant and randnin perio is belonger to the nome ranch, we obt:'aner $T_{\text {iest }}=\mathrm{T}_{I} / 3$, though from a statistucal nount of viel it is imposible

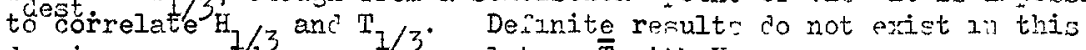
domein, we wouth sucsest 3 orrelatine $\overline{\mathrm{T}}$ with $\mathrm{H}_{1 / 3^{\circ}}$

\subsection{Conclusion.}

With : first cerles of rerioric waves exern"ents we have obtrune? the destruction of the break' 'ater' = cover-layer for cifferent storr duration $t$, by vorying $H$ and $T$. The moss of armor unds remained constant. The anule of the slope, occoring to the rerore equilibriul profile could be conoidered as conctunt. For the destruction. cases we ohtained a risk criterion:

$$
\frac{t}{T}=\cdots \log \left(\frac{H^{2}}{\nu T}\right)+B
$$

which provicies the stom duration $t$, knowing $H, T$ and $\nu$.

Then for a second serles of randors w'nd jenerrte? weves experiments we eliminated $t$ and notired that the constant perıocic wave height (H ${ }_{\text {dest. }}$ ) is equal to the simificant wave hel ght $z_{3}$ of random wavos. ThIE Is an experimental demonstration of the justlfibible use of $11 / 3$ as "project wave height".

\section{SUGGESTIONS FOR FURTHER RISIIARCH}

The restructed research time as well as some oroblems with laboratory facilities did not permit us to atudiv ov:r asfect of the regular an ${ }^{3}$ wind generated action on rubble-mound breakwaters. The flow is

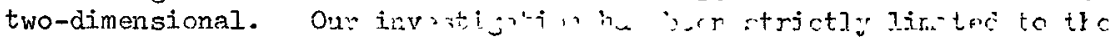
"ffects of these two types of rave artion on the structure. It was technically imiossible to study the production of waves by the vind, at the sare time.

There is certainly more to do, and we would suggest the followng:

(a) The seaward face of rubble-mound breakwaters, is we have seen in sections 2.4 and 3.3., is "carved" by wave attwch, durin: the first minutes of the experiment. Therefore variations of the an fle of slope every two degrees do not influence the resulti. Figure 7 illustrates this point. The experimental dest:uction border line is nearly horizontal for varying from 30 to 36 (every 2 ). Fus, there are two, more efficient, ways to experiment with breakwaters: elther to 
retain a constant slove curinj all expermont, or to vary the angle every 5 or 6 cesrees.

(b) We have to choose random vilues for $H$ and $T$ dumn expcrament: 'at', momicdic waves. The statislics stu'y could be then ceneralised.

(c) It would be aiso desirable to meeurc cxactly the stablization tine for the cover-layer, when wave oftinl ind not destroy it.

(d) A relationshin between $\mathrm{H} / \mathrm{F}^{\mathrm{T}} / \mathrm{Z}$ and other characteristics of the power spectrum would permat a reduction in the scatter of the results concerning the comparison between periodic and randon waves.

\section{REFEREMCES}

1. ROGAN", A. J. (IS68: "Comportement des jetóes en enrochements vis-a-vis i. 1 houle". Laboratozre Matzonal d'yydraulique, Chatou, FRANCE. (Thèse presentśe a I'Université de FA_is).

2. LONGUET-HIGGINS, M. S. (1952): "On the statustical distrihu'ion of the heights of sea waves". Journ. Mar. Res. II (3).

3. CARTAICIT, D. B. and LONGUET-HIGGISS, 1. S. (1956): "l'h statistrca ${ }^{-1}$ ztribution of the maxima of a rando' function". Proc. Roy. soc., A 237 (209).

4. VALgIBOIS, J. (1962): "SImllitude dans les essazs de stabulite de digues". Note DR I.N.H. - Chetou.

5. BDRisisk, J. (1963): "Cours sur les asplicatzons des methodes statistiques aux trovaux de recherche sxperimentale". Rapport interme, L.i. F. Chatou.

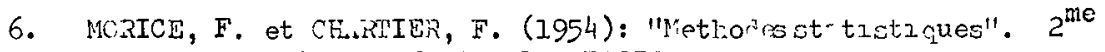
partie. Inprimerie Nationale, PARI,j.

7. BACKN? spectra from the pount of vicw of combuncations engineering". Dover Publ. Inc.

8. WIFCEL, R. (1965): "Oceanographzcal In jinecring". Prentice Hall Int. Serics in Theor. and Appl. Niech. 

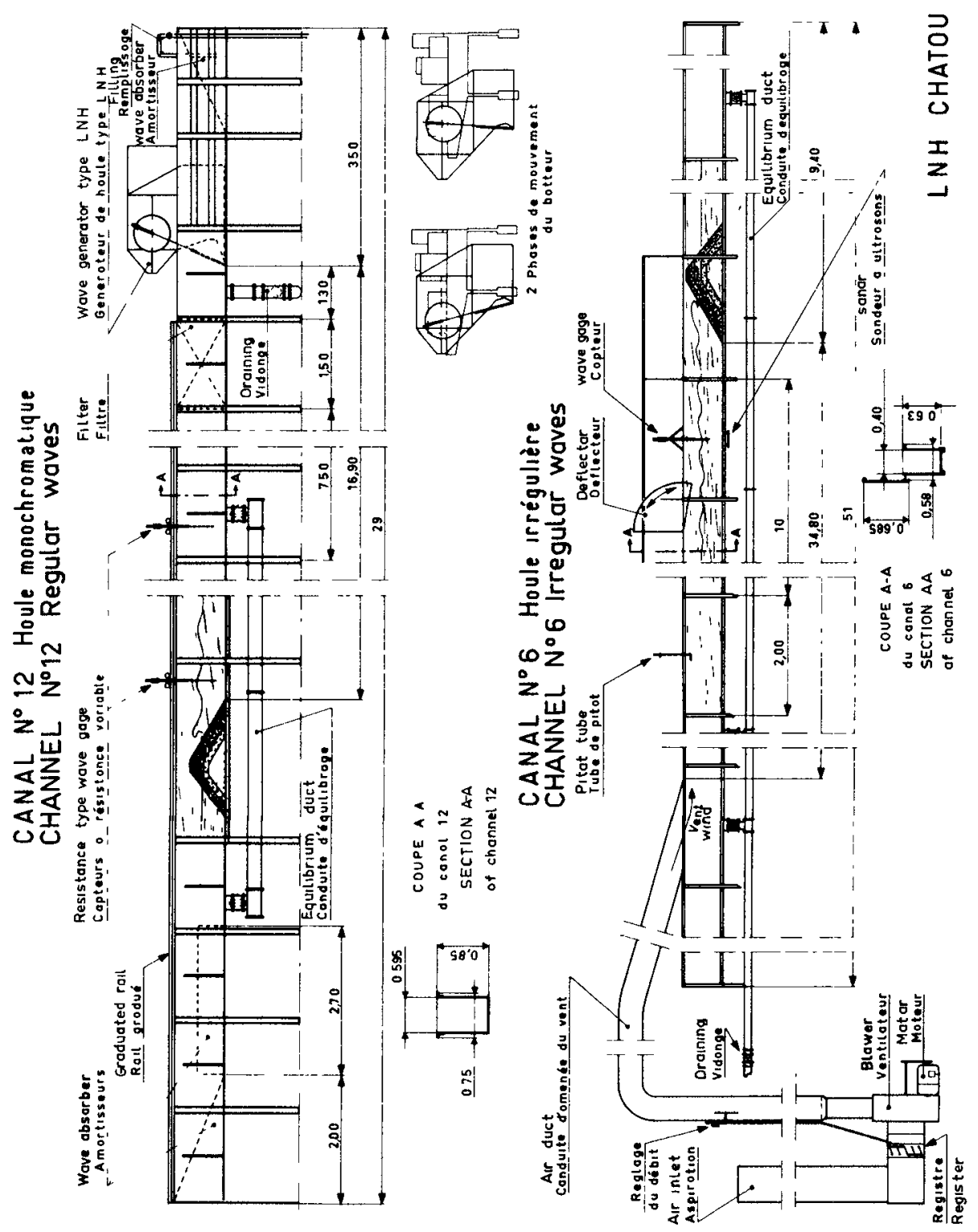

Figure 1 
2eme PROFIL

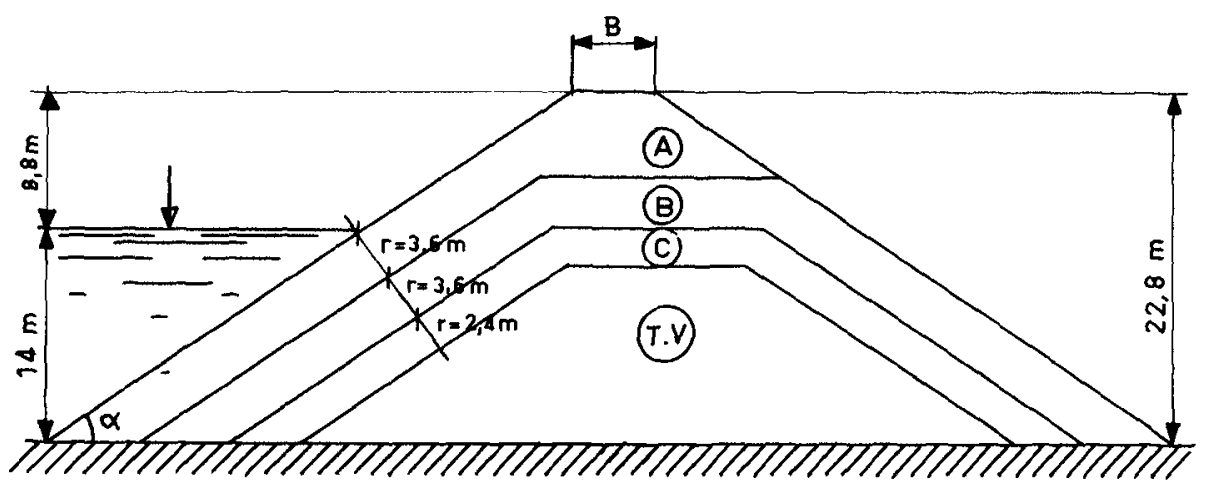

Figure 2

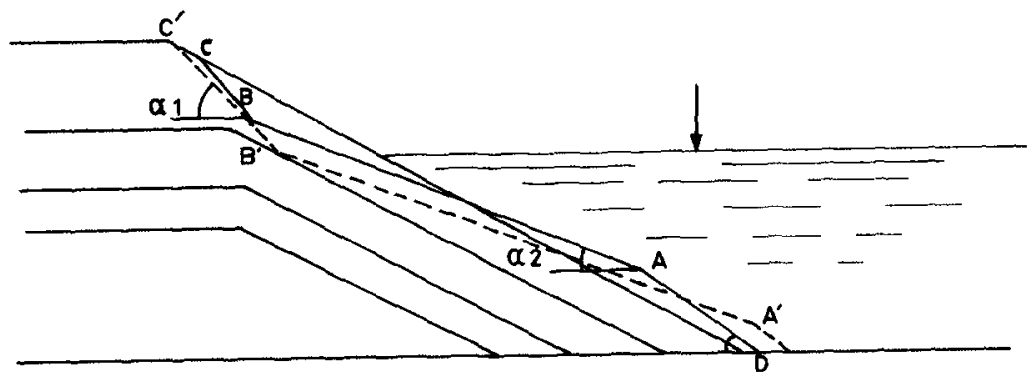

Figure 3 


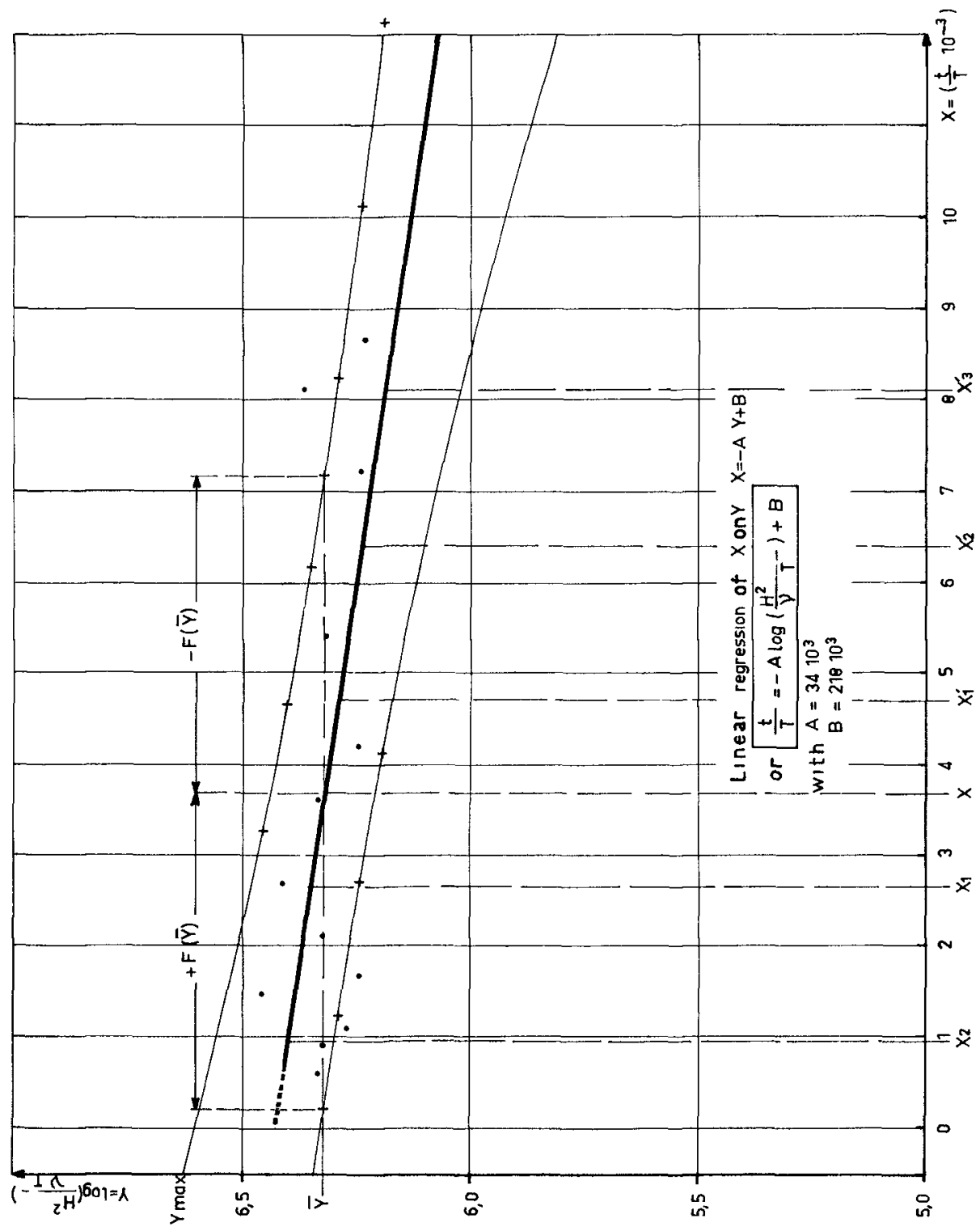

Figure 4 

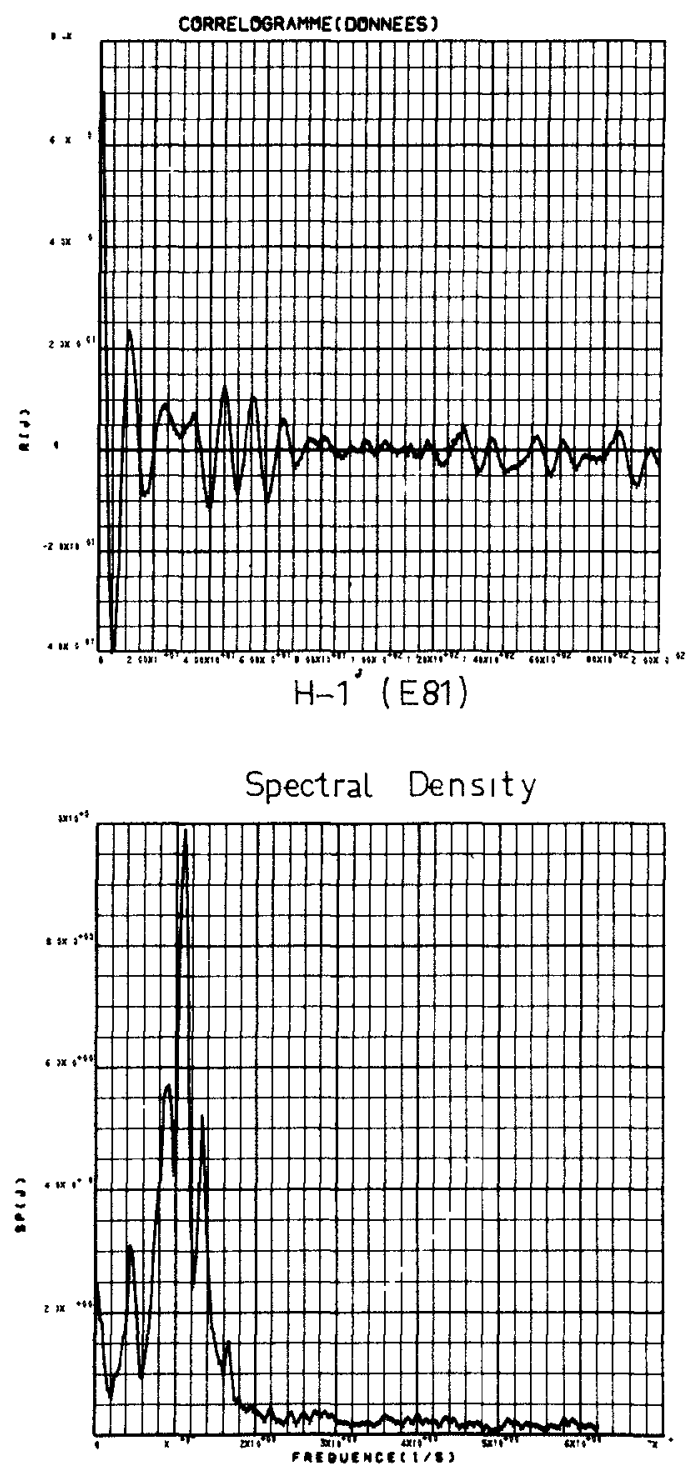

Figure 5 


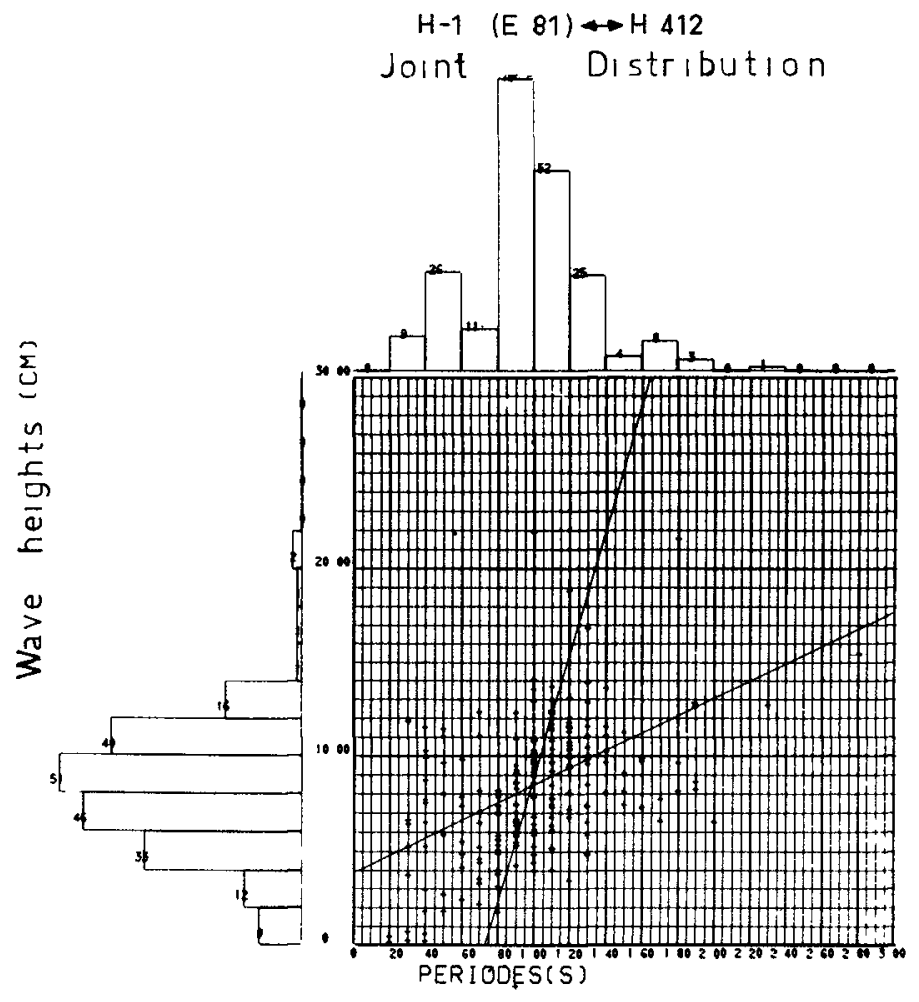

Figure 6

$\begin{array}{lllll}\bar{H} & =8,47 \mathrm{~cm} & t=43,210^{3} \mathrm{~s} & \bar{T}=0,99 \mathrm{~s} \\ H_{\text {dest }}=12,74 " & r=0,37 & T_{\text {dest }}=1,90 \mathrm{~s} \\ H_{\frac{1}{10}}=16,577 " & H_{\text {dest } / H_{\frac{1}{3}}=1,02} & T_{\frac{1}{10}}=1,652 \mathrm{~s} \\ H_{\frac{1}{3}}=12,536 " & H_{\text {dest } / \bar{H}}=1,50 & T_{\frac{1}{3}}=1,356 \mathrm{~s} \\ H_{\frac{1}{2}}=11,374 " & H_{\frac{1}{3}} / \bar{H}=1,48 & T_{\frac{1}{2}}=1,257 \mathrm{~s}\end{array}$




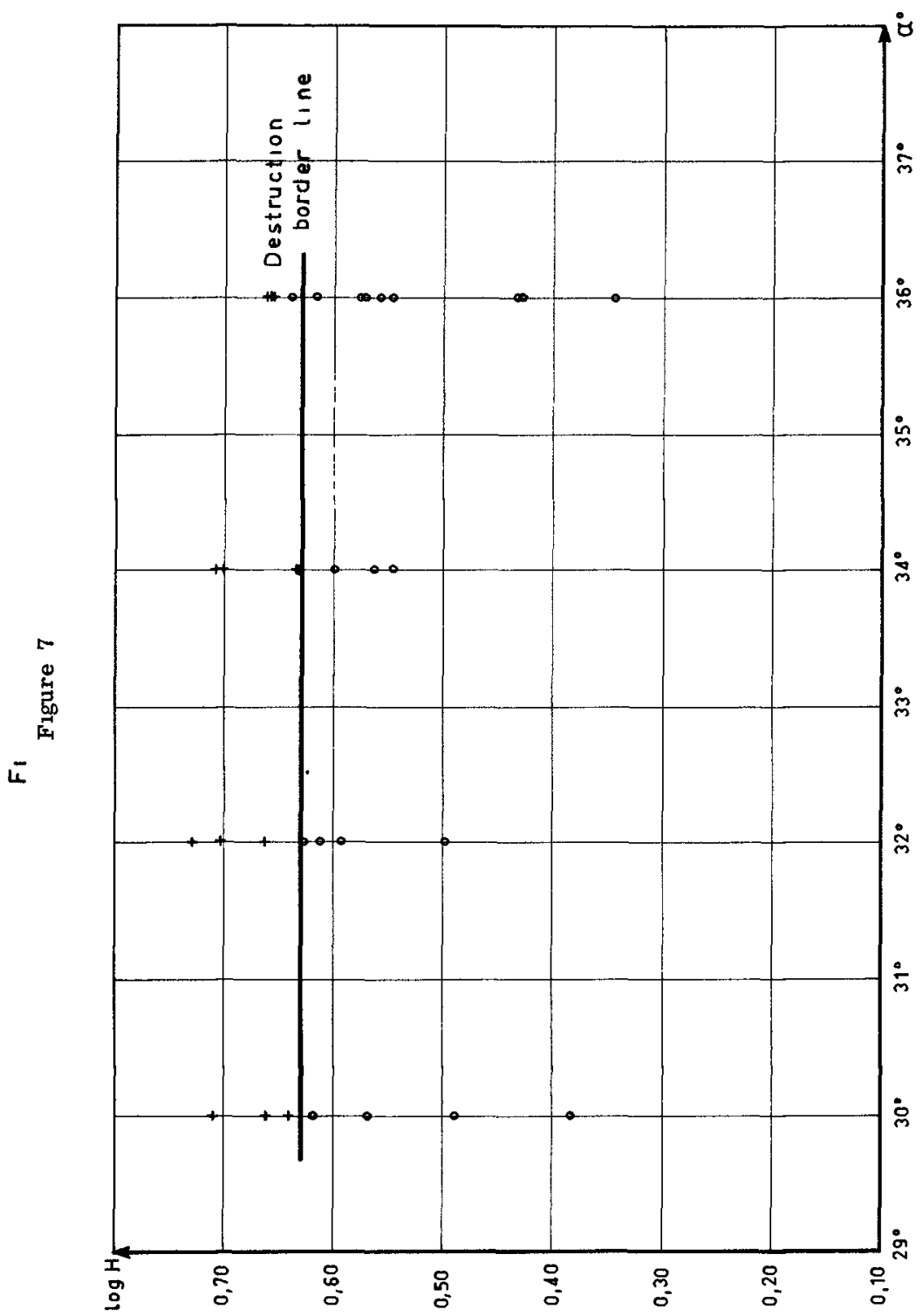

